\title{
Origin of the helical reservoir bubble oxygenator heart-lung machine
}

\author{
Richard A DeWall \\ Wright State Medical School, Dayton, OH, USA
}

\section{Introduction and background}

Thoughts of maintaining life for a short period of time during the exclusion of the heart from general circulation have been acknowledged for nearly 150 years. ${ }^{1-3}$ This concept envisioned a heart-lung bypass machine. The first step to make cardiopulmonary bypass surgery a reality occurred at Johns Hopkins University in 1916. Jay McLean, a medical student who worked in Dr William Howell's laboratory, discovered a substance that would make bypass surgery possible. ${ }^{4}$ Dr Howell named this agent heparin, which proved to be an anticoagulant. ${ }^{5}$

Dr Charles Best in Toronto became aware of Dr Howell's research with heparin. Dr Best, along with his colleagues Drs Charles and Scott, proceeded to purify heparin and reported on this research in $1927 .{ }^{6}$ Dr Best was the codiscoverer of insulin in 1922. In 1937, Dr John Gibbon Jr. employed the first use of heparin in an extracorporeal system to successfully perfuse cats; Dr Best supplied the heparin. Dr Gibbon's first oxygenator was a vertically oriented cylinder in which blood filmed down its interior wall. ${ }^{7}$

After the second world war, Dr Gibbon continued work with extracorporeal circulation using a newly designed parallel screen oxygenator. This system achieved clinical success in May 1953. His subsequent efforts were disappointing. At the same time, many medical centers around the world experimented with their own pump-oxygenator systems. In 1946, using heparin purified in Sweden, Professor Clarence Crafoord and Mr E Andersson, an engineer associate in Stockholm, developed a rotating disc oxygenator. Dr Viking Björk experimented with the Crafoord apparatus and made technical improvements to the system over the course of 1.5 years. ${ }^{8} \mathrm{Dr}$ Frederick Cross popularized the rotating disc oxygenator in the USA in $1956 .{ }^{9}$

Address for correspondence: RA DeWall, MD, 421 Thornhill Road, Dayton, OH 45419-2932, USA.

E-mail: radwll@cs.com
In 1951, at the University of Minnesota, Dr Clarence Dennis published the results of his clinical experience using his rotating screen oxygenator. ${ }^{10}$ Although this clinical trial with a new type oxygenator was unsuccessful, Dr Dennis and his team set the stage for open-heart surgery to become a reality at the University of Minnesota. In the era of the 1950s, the pediatric cardiologists at the University of Minnesota were treating a large number of children with congenital intracardiac defects. The urgency to develop a pump-oxygenator system to facilitate open-heart surgery became apparent.

Dr Owen Wangensteen, who was the Chairman of the Department of Surgery at the University of Minnesota, required all surgical faculty members and residents to work in some aspect of surgical research. In the late 1940s and early 1950s, several faculty members were involved in cardiac surgeryrelated research. One faculty member, Dr C Walton Lillehei, developed his interest in non-open-heart surgery, working under the direction of his mentor Dr Richard Varco, the chief of heart surgery. The scene was set for the development of open-heart surgery at the University of Minnesota.

In the early 1950s, interests heightened in the international surgical world to find a way for the surgical repair of intracardiac defects. In 1952, Dr Morley Cohen began his surgical research working in Dr Lillehei's laboratory. A 1952 report by Drs Andreasen and Watson found that a dog could survive for 0.5 hours without clinical harm with only the blood flow from its azygos vein. ${ }^{11}$ They called their observation the 'azygos factor.' Drs Lillehei and Cohen realized that this information could be applied to their research. The azygos blood flow represented approximately $10 \%$ of the cardiac output.

Presented 1 February 2003, at the annual seminar of the American Academy of Cardiovascular Perfusion, special symposium 'A Celebration of 50 Years of Cardiopulmonary Bypass', Coronado, California. 
Dr Cohen envisioned using a portion of the dog's own lung as an oxygenator. For a pump, he chose a common laboratory pump that could be accurately calibrated to deliver a balanced blood flow between the arterial and venous components of his laboratory model. The approach was to cannulate a pulmonary vein and remove an amount of arterialized blood equal to $10 \%$ of the dog's expected resting cardiac output. The blood would be pumped into the systemic arterial system of the animal. Venous blood was removed from the dog's vena cavae and pumped, in an amount balancing the arterial withdrawal, into its pulmonary artery. Both vena cavae were occluded at their junction with the heart. The method was now established to provide complete circulatory bypass of the dog's heart to permit openheart surgery. ${ }^{12}$

Dr Cohen's wife was pregnant when the autogenous lung oxygenator studies neared completion. The maternal fetal placenta connection suggested to Dr Cohen that this relationship represented an ideal blood donor/recipient patient support system. (Personal communication with Dr Morley Cohen, 14 January 2003.) Dr Cohen initiated a laboratory experiment that used two dogs, a donor and a smaller (pediatric) recipient.

Dr Warden joined Dr Cohen in Dr Lillehei's laboratory in mid-1953 to work on the donor/patient animal experiments. Their experiments joined the animal's arterial and venous circulatory systems with plastic conduits. The blood flow between the two animals was controlled in the range of between $20 \%$ and $40 \%$ of the recipient's normal cardiac output by a calibrated occlusive pump. In this manner, the recipient dog's heart could be bypassed and opened for an intracardiac surgical procedure. The connection of the circulations between a donor and a patient became known as controlled crosscirculation (Figure 1).

The first open-heart surgery performed by $\mathrm{Dr}$ Lillehei using the support of controlled cross-circulation occurred on 24 March 1954. The patient was a 13-month-old child with a ventricular septal defect. A total of 45 patients with congenital heart disease were operated upon using controlled cross-circulation. ${ }^{13}$

\section{Development of the helical reservoir pump- oxygenator}

The preceding story provides a background for the status of heart surgery before I became involved. I served a military internship from mid-1952 to mid1953. One of my patients, at that time, was a young seaman with severe rheumatic valvular heart disease. There was no curative procedure available. That caused me to think of the heart as a pump with internal valves. Pumps with valves existed for hundreds of years. Why could not the heart be opened and the valves repaired as with any other pump?

The Korean War was over in 1953 and I was discharged from the service after completing my year of internship. I returned to my home city of Minneapolis, Minnesota, and worked in general practice. Periodically, I thought of my patient with rheumatic heart valve disease. Solutions to openheart surgery had not yet been devised. Not knowing how to directly approach the diseased valve problem, I carved a prototype flutter valve from plaster of Paris. I did not know what to do with this valve until I thought of talking to one of my medicalschool teachers, Dr Richard Varco, the chief of heart surgery at the University of Minnesota.

I went to the university and found Dr Varco in the operating room suite. He kindly received me. We sat on a litter outside of his operating room and I discussed valve surgery with him and showed him my plaster prototype. Dr Varco said he would try to help me work on the problem and that one of his colleagues had a heart surgery research laboratory. Dr Varco arranged for me to meet with Dr C Walton Lillehei.

In February of 1954, I met with Dr Lillehei who took me to his animal laboratory. There, I was introduced to Dr Herbert Warden. After some discussion they asked me to join them working in the animal laboratory. Dr Warden directed the laboratory and was well along with his work on controlled cross-circulation. Dr Lillehei said that, since all the surgery resident appointments had been filled for the year, there was no money available for an additional surgical resident. He did say that the surgical research fund had money to pay me as an animal attendant. Since I was interested in laboratory medicine and never considered myself a surgery resident candidate, to be employed as an animal attendant was perfectly acceptable. An animal attendant had an advantage over the surgical resident: the pay was better.

On 1 March 1954, I began work under the direction of Dr Warden in Dr Lillehei's laboratory. Perfusion physiology of controlled cross-circulation was the main emphasis of the laboratory work. Dr Warden was an excellent teacher. After eight months of controlled cross-circulation laboratory study by Dr Warden, and to a limited extent myself, the procedure was transferred to the operating room 


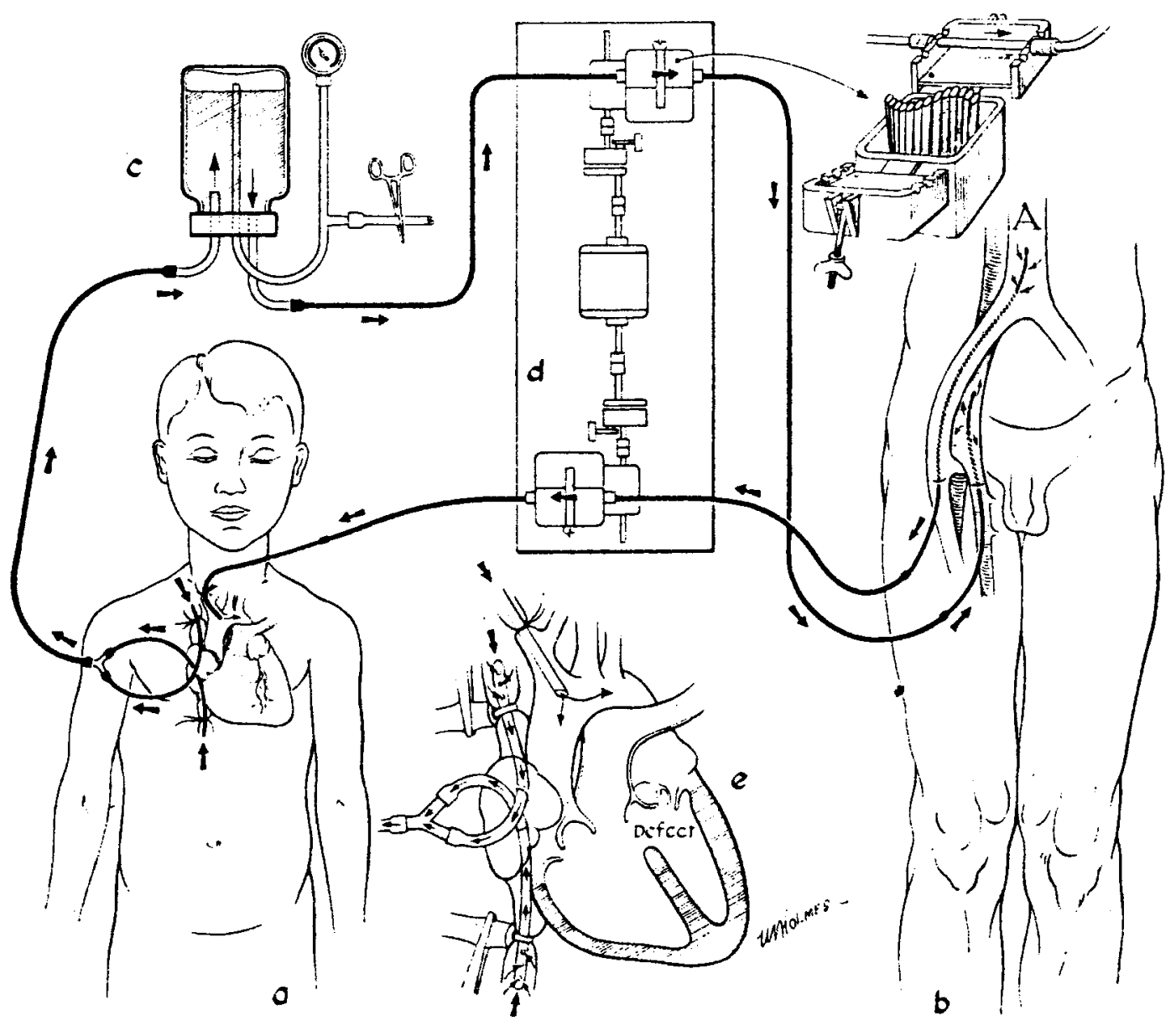

Figure 1 Drawing of the controlled cross-circulation relationship between a donor (b, on right) and a smaller (pediatric) recipient (a, on left). The donor's femoral artery and vein were cannulated and connected to plastic tubes, which ran through a rate-controlling occlusive 'finger' pump (d); a magnified view (upper right) shows the pumping mechanism. Arterial donor blood was delivered to the recipient's systemic circulation by the pump via a catheter inserted into the right or left subclavian artery. As blood was diverted away from the recipient's heart from the vena cava, it passed through a venous reservoir and air trap (c, upper left). A magnified view of the heart (e) shows vena caval cannulation with occluding tapes for securing inflow stasis, which permitted the heart to be opened for intracardiac repair of septal defects. (Reprinted from Lillehei CW et al. Surgery 1955; 38: 13, with permission.)

for support of pediatric open-heart surgery cases. The task of perfusionist was assigned to me. ${ }^{14}$

Dr Lillehei's clinical program that used controlled cross-circulation was the only open-heart surgical program in the world. It attracted a great many surgeons from the world's major surgical clinics. The procedure had two great advantages: the first advantage was that it worked, and the second was it was cost effective. As the world was still recovering from the second world war, funding for healthcare was scarce in many major medical centers.

One afternoon after the day's work, Dr Lillehei mentioned to me that it would be desirable to find a substitute for the donor in the cross-circulation procedures. A reliable heart-lung machine was needed because other oxygenator systems at that time had not demonstrated their general usefulness. Dr Lillehei suggested research on a heart-lung machine as a good project for me if I were interested.
He also mentioned that, if the project appealed to me, I should avoid all library research on the subject in order to keep an open mind. Dr Lillehei's other admonition to me was to avoid bubble oxygenator systems as they had a poor history for clinical success.

I began my research project on 1 July 1954. I continued as perfusionist for the open-heart crosscirculation procedures in the mornings and did my laboratory research in the afternoons and evenings. At the time that I began my research, two methods were apparent for the exposure of blood to an oxygen phase in an extracorporeal system. One system created a thin film of blood in an oxygen atmosphere. The other created bubbles by channeling fine streams of oxygen into the blood. Seven primary variables influenced the oxygenation of blood in an extracorporeal system. These variables were: 1) the thickness of the blood film either as a 
film or a film surrounding a gas phase - a bubble (the thickness of the blood film affected the diffusion gradient of oxygen into the blood); 2) the time required for exposure of blood to the gas phase (the rate at which oxygen and hemoglobin react is almost instantaneous, ${ }^{15}$ (and the time for oxygen to diffuse through the plasma is the effective time for oxygenation); 3) the $\mathrm{pO}_{2}$; 4) the $\mathrm{pCO}_{2}$; 5) the $\mathrm{pH} ; 6$ ) the temperature; and 7) the bubble size (smaller bubbles retained carbon dioxide to a greater degree than larger bubbles).

Recalling Dr Lillehei's admonition to avoid bubbles, I made a number of experiments using filming techniques. All these efforts failed. As hyperbaric systems for the oxygenation of blood had never been tried, I calculated that blood exposed to three atmospheres of oxygen put six volumes percent of oxygen into the blood. This is equivalent to a normal arteriovenous oxygen difference even in the absence of erythrocytes.

Dr Lillehei also suggested that I might find some use of a polyvinyl chloride (PVC) hose such as used in the food industry. The use of a plastic material was fortuitous. Studies had demonstrated that a glass surface was deleterious to various blood clotting factors. ${ }^{16}$

It was apparent that blood could be filmed by flowing down a long inclined tube. The blood flow rate could be controlled by the rate of blood infusion into and out of the tube and the incline of the tube. A six-foot long tube, which was placed at a $45^{\circ}$ angle, served as the oxygenator. Pressurized oxygen flushed the space above the blood flowing down the tube. A rubber cork at the bottom of the tube contained a port for the removal of blood. An oxygen input device was placed between the middle and the lower third of the tube.

A rubber cork, which contained a venous input port and an exhaust port for the removal of respiratory gases, capped the top of the tube. The exhaust port contained a pressure gauge, which controlled the gas pressure within the tube at three atmospheres. The blood-filled lower third of the tube served as a reservoir. The blood flow in and out of the tube was maintained with an occluding pump. Because the six-foot long tube was cumbersome, it was wrapped around a stand to make a helical oxygenator and reservoir. The next stage of my oxygenator development used this reservoir.

I made a major miscalculation with the hyperbaric system. I had not considered the effects of decompression. The blood must be decompressed to normal atmospheric pressure before it is returned to the animal. Although hyperbaric experiments did not provide a prototype for a useful pump-oxyge- nator, several useful observations proved valuable. Upon decompression, oxygen formed blood bubbles and foam as the oxygen came out of solution. As the decompressed blood flowed in and out of the coiled tube, the lighter bubbles would skim off of the top of the bubble-free blood, which flowed beneath the bubble and foam layer along the inclined plane. This bubble-free blood proved safe to infuse into the animal or patient.

Bubbles presented a problem to any oxygenator system. I realized that I had to learn to manage bubbles. A concept of a bubble oxygenator came to mind. I used a 2-ft-long segment of hose and placed it in a vertical position. A rubber cork perforated by 18 number 22 hypodermic needles was inserted at the base of the vertical tube, which would produce bubbles in contrast to foam. Foam is more difficult to remove from blood than the larger bubbles.

A second 2-in-long matching hose segment was closed at its lower end with a cork. The short hose segment was attached to the bottom of the vertical

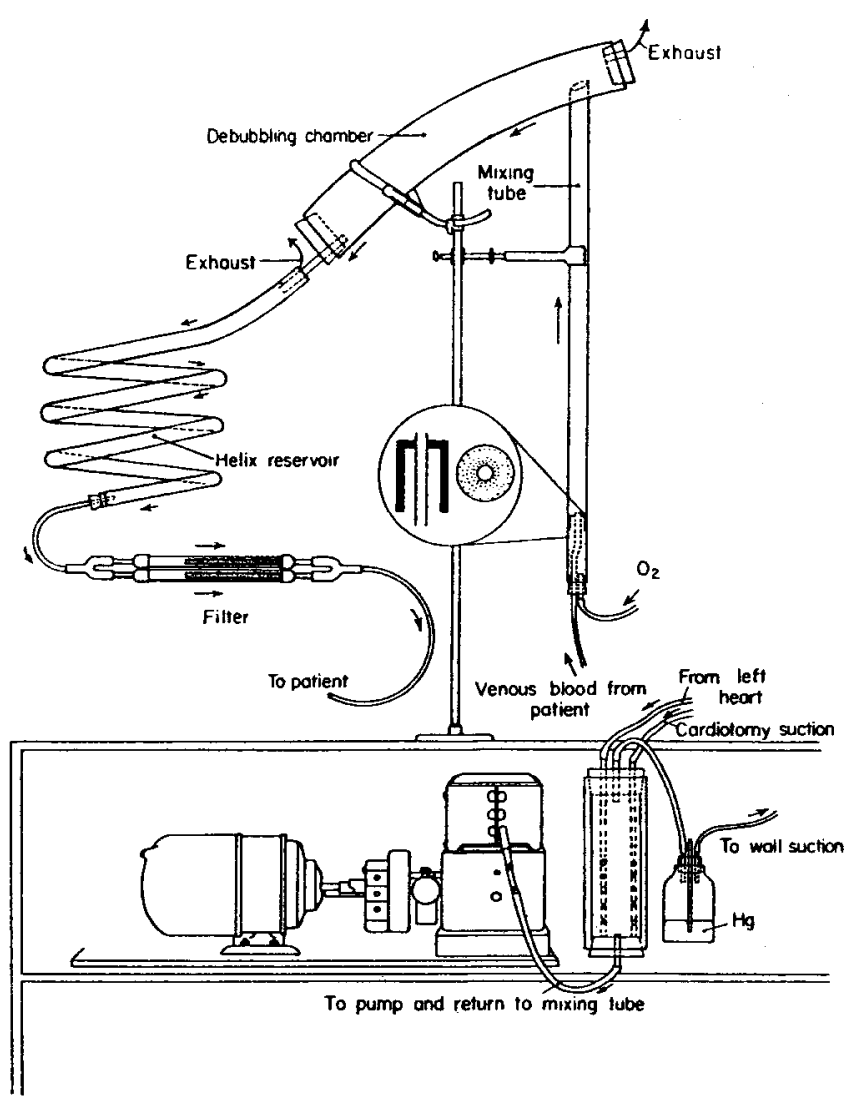

Figure 2 Drawing of the helix reservoir pump-oxygenator. This apparatus had five essential components: blood/oxygen mixing tube (vertical, on right); large debubbling chamber (diagonal, on top); helix reservoir (left); filter (horizontal, at bottom left); and cardiotomy blood reservoir (lower level, on right) with its own pump to return blood to the afferent limb of the oxygenator. (Reprinted from DeWall RA et al. Surg Gynecol Obs 1957; 104: 701, with permission.) 
tube to contain and direct the oxygen flow through the hypodermic needles. A quarter-inch internal diameter hose was placed through the lower chamber and into the vertical tube, emerging between the hypodermic needles. With the flow of oxygen, venous blood bubbles formed at the base of the vertical tube, absorbed oxygen, and released carbon dioxide as it rose to the tube top. The top of the vertical tube was bent in the fashion of a cane handle.

A smaller tube then directed the blood into the top of the helical reservoir. Blood bubble contact with plastic surfaces such as PVC had some debubbling effect. The helical reservoir served to eliminate any residual bubbles. When blood left the helical reservoir, it passed through a filter such as was used with donor blood bottles (Figure 2).

Silicone was used as a standard coating for blood collection bottles in the early 1950s. The silicone coating protected the blood from the effects of glass and served as a defoaming agent when in contact with blood bubbles. ${ }^{17}$ With this in mind, I used a silicone coating on the surface of the connecting segment between the bubble generator and the helical reservoir.

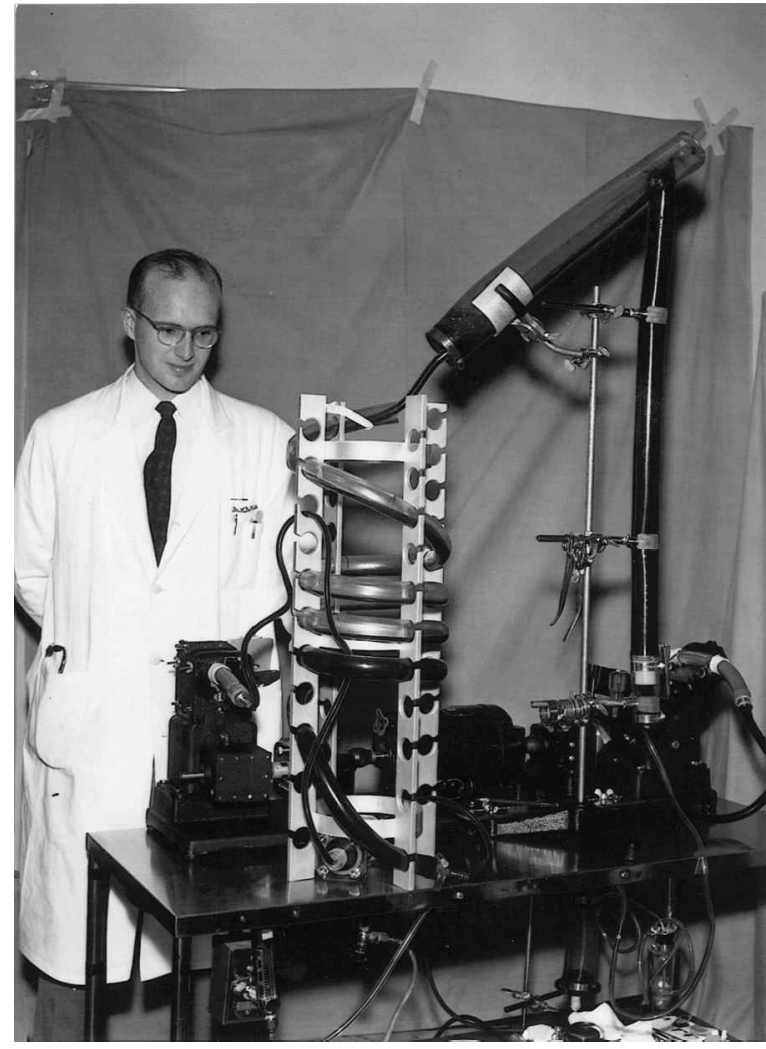

Figure 3 Photograph of Dr DeWall with the helical reservoir pump-oxygenator as it was prepared for clinical use. All components of the system were assembled and autoclaved the day before each case.
The first oxygenator was suitable only for patients under 20 pounds $(9 \mathrm{~kg}$ ), but increasing the system's dimensions allowed patients of any size to be supported (Figure 3). Each increase in the system's size was tested in animal perfusions before it was used in human applications. This testing assured success at higher perfusion rates. ${ }^{18}$

Many surgeons visited both the Mayo Clinic and the University of Minnesota to observe work in open-heart surgery. The Mayo Clinic initiated a successful open-heart surgery program on 22 March 1955 with the repair of a ventricular septal defect in a child. They used a modified Gibbon vertical screen oxygenator that was contained in a large stainless steel console, which they had developed over the preceding year. ${ }^{19}$

The first clinical use of the helical reservoir pump-oxygenator occurred on 13 May 1955. The patient was a three-year-old boy with a ventricular septal defect. The system worked well if one understood both the surgical and perfusion principles. The machine was cost effective. It could be assembled from materials available in all parts of the world and it was disposable after one use. Because of these factors, the system was widely accepted and

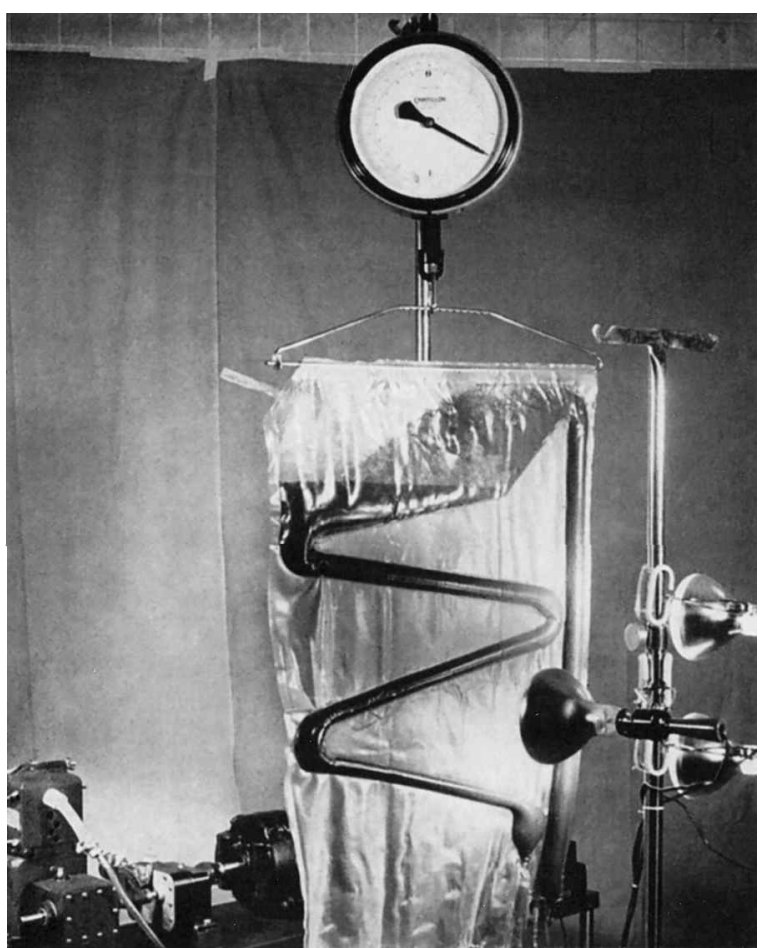

Figure 4 Photograph of the disposable flat-sheet bubble oxygenator and Sigmamotor finger pump (lower left). The suspending spring scale allowed instantaneous assessment of blood volume during perfusion. Infrared lamps (right) directed on the settling chamber minimized heat loss. (Reprinted from Gott VL et al. Dis Chest 1957; 32: 617, with permission.) 


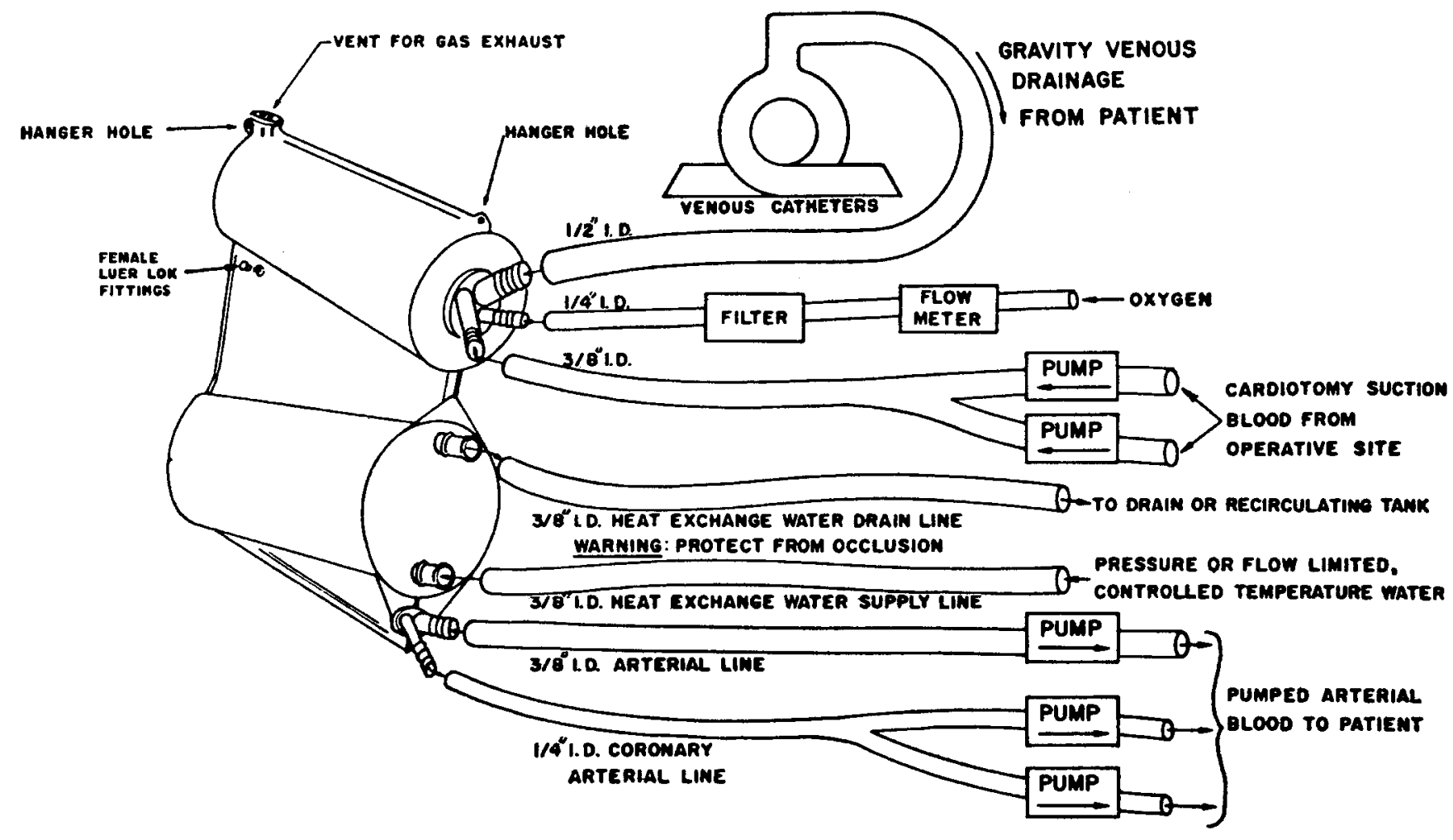

Figure 5 Drawing of hard-shell temperature-controlling disposable blood oxygenator. Venous blood drained by gravity to the upper cylinder and mixed with cardiotomy suctioned blood delivered directly from the operative site by minimally occlusive roller pumps. The blood/gas mixing chamber contained a silicone-coated coarse polypropylene mesh covered in nylon tricot to remove bubbles. The lower chamber was the arterial reservoir and contained a graphite-coated canister for temperature stabilization, which relied on circulating water. (Reprinted from DeWall RA et al. JAMA 1966; 197: 1067, with permission.)

used with increasing frequency for open-heart surgery.

As surgeons learned the pathologic physiology of congenital heart disease and, especially, how to take care of the post-perfusion patient, there was a demand for a system that did not have to be handmade before each operation. The Travenol Division of Baxter Laboratories aided the development of the disposable sheet oxygenator and became its manufacturer. ${ }^{20}$ Two sheets of PVC were fused together forming channels incorporating the helical reservoir concept. The Baxter unit answered the need (Figure 4).

As the complexity of procedures developed, temperature control of the patient became a concern. This concern led to the development with $\mathrm{Mr}$ Donald J Bentley in Santa Ana, California, of a three-dimensional hard-shell disposable system incorporating a heat exchanger called the Bentley Temptrol (Figure 5). ${ }^{21}$

From the beginning of my experience with extracorporeal oxygenation of blood, thoughts of duplicating the human lung frequently came to mind. I made prototypes of such a capillary membrane system; however, the work was not completed and was never published. It did appear as a patent and as the Dow Corning dialyzer. ${ }^{22}$ From the start of treating my patient with rheumatic valvular heart disease, I achieved a goal of helping patients with intracardiac defects.

\section{Summary}

Open-heart surgery was not possible before the early 1950s. Such surgery awaited the development of cardiopulmonary bypass. The development of controlled cross-circulation at the University of Minnesota in 1953 was a major contributing factor towards operating safely on the interior of the heart. Crosscirculation required connecting a donor's arterial and venous blood vessels to those of a smaller recipient whose heart could then be opened for corrective surgery. At that time, no mechanical system was available to serve the role of the donor. The need to replace the donor as soon as possible was recognized. The author has recounted his experience with the development of a bubble oxy- 
genator system, which replaced the donor as was used in cross-circulation open-heart surgery.

\section{References}

1 LeGallois JJC (1770-1814). Quoted and illustrated in Griffenhagen GB, Hughes $\mathrm{CH}$. The history of the mechanical heart. Annu Rep Smithsonian Instit 1955. Publication No. 4241: 339-56. (Original citation: LeGallois JJC: Experiences sur le principle de la vie. Paris: D’Hautel, 1812. Translation by NC Nancrede, JG Nancrede. Experiments on the principle of life. Philadelphia, 1813.)

2 DeWall RA, Grage TB, McFee AS, Chiechi MA. Theme and variations on blood oxygenators; I. Bubble oxygenators. Surgery 1961; 50: 931-40.

3 DeWall RA, Grage TB, McFee AS, Chiechi MA. Theme and variations on blood oxygenators; II. Film oxygenators. Surgery 1962; 51: 251-57.

4 McLean J. The thromboplastic action of cephalin. Am J Physiol 1916; 41: 250-57.

5 Howell WH, Holt E. Two new factors in blood coagulation, heparin and proantithrombin. Am J Physiol 1918; 47: 328-41.

6 Charles AF, Scott DA. Studies on heparin: observations on the chemistry of heparin. Biochem J 1936; 30: $927-$ 33.

7 Gibbon JH Jr. Artificial maintenance of circulation during experimental occlusion of pulmonary artery. Arch Surg 1937; 34: 1105-31.

8 Björk V. Brain perfusions in dogs with artificially oxygenated blood. Acta Chir Scand 1948; 96 (Suppl 137): 3-122.

9 Cross FS, Berne RM, Horose U, Kay EB, Jones RD. Evaluation of rotating disc type of reservoir oxygenator. Proc Soc Exp Biol Med 1956; 93: 210-14.

10 Dennis C, Sprang D, Nelson G et al. Development of a pump-oxygenator to replace heart and lungs; an apparatus applicable to human patients and application to one case. Ann Surg 1951; 134: 709-21.

11 Andreasen AT, Watson F. Experimental cardiovascular surgery. Br J Surg 1952; 39: 548-52.
12 Cohen M, Lillehei CW. Autogenous lung oxygenation with total by-pass for intracardiac surgery. Surg Forum 1953; 4: 34-40.

13 Warden HE, Cohen M, Read RC, Lillehei CW. Controlled cross-circulation for open-heart intracardiac surgery. J Thorac Surg 1954; 28: 331-43.

14 Lillehei CW, Varco RL, Cohen M, Warden HE, Patton C, Moller JH. The first open-heart repairs of ventricular septal defects, atrioventricular communis, and tetralogy of Fallot using extracorporeal circulation by crosscirculation: a 30-year follow-up. Ann Thorac Surg 1986; 41: 4-21.

15 Hartridge H, Roughton FJW. The kinetics of haemoglobin II. The velocity with which oxygen dissociates from its combination with haemoglobin. Proc $R$ Soc 1923; 104: 395-98.

16 Rapaport SI, Aas K, Owren PA. The effect of glass upon the activity of the various plasma clotting factors. J Clin Invest 1955; 34: 9-19.

17 Clark LC Jr, Gollan F, Gupta VB. The oxygenation of blood by gas dispersion. Science 1950; III: 85-87.

18 DeWall RA, Warden HE, Read RC et al. A simple expendable artificial oxygenator for open-heart surgery. Surg Clin N Am 1956; 36: $1025-34$.

19 Kirklin JW, DuShane JW, Patrick RT et al. Intracardiac surgery with the aid of a mechanical pump-oxygenator (Gibbon type): report of eight cases. Proc Staff Meet Mayo Clin 1955; 30: 201-206.

20 Gott VL, DeWall RA, Paneth M et al. A self-contained disposable oxygenator of plastic sheet for intracardiac surgery. Thorax 1957; 12: 1-9.

21 DeWall RA, Najafi H, Bentley DJ, Roden T. A hard shell temperature controlling disposable blood-oxygenator. JAMA 1966; 197: 1065 -71.

22 United States Patent. Richard A DeWall, capillary oxygenator, \# 2,972,349. 1958. 
Copyright $\odot 2003$ EBSCO Publishing 
Copyright $\odot 2003$ EBSCO Publishing 